\title{
Varieties of Employment Subsidy Design: Theory and Evidence from Across Europe
}

\author{
AXEL CRONERT (i) \\ Department of Government and Uppsala Center for Labor Studies, Uppsala University, \\ Sweden \\ email: axel.cronert@statsvet.uu.se
}

\begin{abstract}
Employment subsidy programs have experienced considerable expansion across Europe in recent decades. To date, most studies analyzing this policy shift have assumed that these programs are largely equivalent in terms of their designs, effects, and explanations. In contrast, this article argues that employment subsidies are best understood as versatile multi-purpose tools that can be used as means to rather different distributional ends. Using Multiple Correspondence Analysis to explore novel data from hundreds of employment subsidy programs across Europe, this article develops a new typology based on two overarching trade-offs. The typology highlights that employment subsidies may be designed to counteract as well as to sustain insider/outsider divides in the labor market, and that they may be designed to tackle either structural or cyclical labor market problems. In a first empirical evaluation of the typology, programs with different designs are found to vary systematically in terms of distributional outcomes and starting conditions.
\end{abstract}

\section{Introduction}

Few scholarly accounts of modern European welfare states fail to mention the shift toward 'activation' in social and labor market policy since the 1990s to promote employment growth. Alongside supply-side reforms to increase job search activity among those out of work, perhaps the most evident manifestation of this shift is the expansion of demand-side employment subsidy programs meant to motivate employers to increase the employment or earnings of disadvantaged workers. Indeed, during the decades of 'permanent austerity', employment subsidies - described by the European Commission (2014: 6) as 'symbolic' of this shift - roughly doubled in scope in the EU-15, from 0.086 percent of GDP in 1985 to 0.171 in $2011^{1}$ (OECD, 2017). The European Commission itself is often viewed as having played a key role in promoting these developments by adopting policy recommendations, enabling mutual learning among experts and policymakers, and providing financial support (Weishaupt, 2011).

To many scholars, the shift toward activation represents a profound break with the institutional regimes that have defined the distinct trajectories of European welfare states in the post-war era. Some suggest that these policies 
form part of a new post-national regime based on 'Schumpeterian workfare', which is 'tendentially replacing' post-war welfare arrangements, albeit with varying paces and national expressions (Jessop 1993; 1999: 348). Others emphasize persisting national differences, but even they observe a regime-transcending upward trend in employment subsidy expenditures (Graziano, 2012; Bonoli, 2013) and, indeed, a 'major convergence in designing the set of rules and instruments' of activation policies across regimes (Eichhorst et al., 2008: 432).

In the wake of these developments, scholars have begun to take an interest in employment subsidies in their own right, examining how their effects (Card et al., 2015) and explanations (Nelson, 2013; Vlandas, 2013) differ from those of other types of active labor market policy (ALMP), such as labor market training or direct job creation. This article addresses a shortcoming of most such research to date, namely the tendency to treat employment subsidies as a uniform subcategory of ALMP, assuming that their designs, effects, and explanations are largely equivalent. Using new and rich data from the EU LMP database, this article is able to disprove that assumption and make a twofold contribution to the welfare state literature.

The first contribution is to introduce in three steps a typology of employment subsidy programs based on their intended labor market effects. First, I review the major choices involved in subsidy design, as detailed in the labor economics literature (Bishop and Haveman, 1978; Katz, 1998; Brown and Koettl, 2015). Next, using Multiple Correspondence Analysis (MCA), I explore the statistical associations among all of these choices as observed for hundreds of programs across the EU-27 and Norway to identify and interpret the underlying dimensionality of employment subsidy design. I find that the lion's share of the variation can be reduced into two dimensions, representing two overarching design trade-offs: to what extent the subsidy is targeted primarily to the 'outsiders' in the labor market; and to what extent the subsidy is devised to alleviate structural rather than cyclical labor market problems. Based on the two dimensions, I then derive a typology of four varieties of employment subsidy programs, for which we can expect distinct distributional effects and explanations. This typology permits more refined analyses of the political economy of employment subsidies than existing analytic frameworks.

The second contribution is to evaluate the plausibility of the proposed typology empirically by testing a set of observable implications on close to 500 programs observed across Europe between 1998 and 2013. The results confirm the relevance of the typology and substantiate the claim that employment subsidies are best understood as versatile, multi-purpose tools that policymakers may use as means to rather different distributional ends. Among other things, this implies that observing a common trend towards more employment subsidies across Europe is not sufficient, per se, to conclude that there is a substantial 
convergence in the underlying institutional logics that govern policymaking in different countries.

\section{Employment subsidies: What they are and how they vary}

Employment subsidies are demand-side labor market interventions that provide economic incentives to employers to increase the employment and/ or earnings of selected groups of persons experiencing difficulties in the labor market. Funding is at least partly provided via the government, whereas hiring and firing decisions ultimately remain in the hands of private firms and, in some cases, public and non-profit employers. Consistent with the theoretical literature on the effects of active labor market policy (Katz, 1998; Neumark, 2013) and the established ALMP databases (Eurostat, 2013), this definition distinguishes employment subsidies from general, non-selective employment or fiscal interventions such as across-the-board reductions in payroll taxes for specific demographic segments of the population or earned income tax credits for people in low-wage employment, for which benefits are equally available to persons who are already working. Additionally, falling outside of the definition are selective supply-side subsidies, such as re-employment bonuses, mobility grants, and childcare allowances, because they serve to affect workers' job search behavior rather than employers' recruitment behavior ${ }^{2}$ (Katz, 1998).

As outlined below, long-standing theoretical work on the effects of ALMP has established that employment subsidies come in a variety of forms with distinct distributional trade-offs. This insight, however, has not yet been sufficiently addressed in the literature devoted to the causal dynamics of ALMP. Indeed, as argued by Clasen et al. (2016: 33-34), this literature is still 'in its infancy' and in 'fundamental need' for a reconsideration of the theoretically relevant dimensions of variation in ALMPs.

Clearly, significant advancement has been made in recent years as scholars have begun to distinguish between different types of ALMP programs, typically based on their intended labor market effects. Hence, employment subsidies are now regularly distinguished from training programs, which are meant to upgrade the skills of the labor force, and from job search programs, which are intended to boost search activity among those out of work (e.g. Bonoli, 2013; Nelson, 2013; Vlandas, 2013). Following Bonoli (2010), employment subsidies are also regularly distinguished from direct job creation programs, as the latter are not intended to promote demand-driven market employment but rather to keep people occupied in non-market jobs of community benefit, usually in the public or non-profit sector.

In addition, scholars have noted that a distinctive feature of employment subsidies is that their implementation requires the joint involvement of employers and the state, whereas most other programs can be produced unilaterally by state actors (Cronert, 2018). In that vein, a number of case studies have analyzed 
how employers perceive employment subsidy programs and how these perceptions matter for their involvement (e.g. Gore, 2005; Ingold and Stuart, 2015; Van der Aa and Van Berkel, 2014). A few studies have extended the scope by comparing employers' perceptions across countries (e.g. Martin, 2004).

Nevertheless, with the exception of two case studies by Martin (2004) and Van der Aa and Van Berkel (2014), the comparative literature on the politics of employment subsidies has largely treated these programs as a uniform sub-category of ALMP, assuming that their designs, expected effects, and explanations are largely equivalent (Bonoli, 2010, 2013; Nelson, 2013; Vlandas, 2013). This assumption is problematic because, as we shall see, the expected effects of an employment subsidy are determined by a long list of design choices, which clearly no analytic framework could exhaust. However, based on a set of in-depth studies on subsidy design, the most fundamental choices can be grouped under six headings: general form of the subsidy, subsidy duration, subsidy rate, transfer type, worker eligibility criteria, and job eligibility criteria.

\section{General form}

Perhaps the most fundamental choice concerns the general form of the subsidy. In essence, the literature identifies two main forms: the general employment subsidy and the recruitment subsidy. The general form subsidizes some portion of total earnings or time spent working for all target group workers at a firm. The recruitment subsidy is paid on some portion of the earnings or time spent working of newly hired workers, as opposed to the firm's total employment. The general design results in more 'infra-marginal subsidization', which refers to subsidization of jobs that would also have been created in the absence of the subsidy. In the short run, such 'windfalls' contribute to the net profits of firms, part of which might be captured by incumbent workers (Bishop and Haveman, 1978; Brown and Koettl, 2015).

\section{Duration}

A second group of decisions concerns the subsidy duration. The longer the possible duration, the more likely the subsidy will succeed in affecting employers' hiring decisions in favor of the targeted group, and the less is the risk of churn - that is, the tendency for firms to lay off workers to replace them with new (subsidized) hires - because the probability that the workers in the target group will adapt to their new environment and improve their skills sufficiently to make them fully productive tends to increase over time (Bishop and Haveman, 1978). This reasoning also suggests that the optimal duration may vary between workers depending on the time they need to catch up. For some particularly disadvantaged groups, it might even be necessary to continue the subsidy indefinitely (Bishop and Haveman, 1978). 


\section{Subsidy rate}

A third choice concerns the Subsidy rate of time spent working or earnings. A higher rate tends to increase demand for target group workers, thereby resulting in greater replacement of non-eligible groups. It also tends to reduce costefficiency and increase windfalls (Bishop and Haveman, 1978). A related choice is whether to apply a Variable rate - based on an assessment of the individual worker's productivity by a caseworker according to certain criteria - or a Fixed rate for all eligible workers. With a variable rate, efficiency can be improved, but the administrative costs incurred by the employers and the state are likely to increase.

\section{Transfer type}

Subsidies can be paid either as a Direct transfer to employers or through the tax system as a Reduction of tax or social security contribution obligations. The former might be more administratively costly and require additional information to be processed by the administrating agency (Katz, 1998), but it might also be more flexible and provide liquidity to employers more quickly than might the tax system-based option.

\section{Worker eligibility criteria}

Any employment subsidy program requires a specification of what workers are eligible for subsidization. These choices, which are decisive for the distributional profile of the program, are typically guided by value judgments about who deserves public support and concerns about what groups are expected to bring about the greatest employment effect per dollar of subsidy. Universal eligibility is generally the least cost-efficient option, particularly compared to subsidies that target socio-demographic groups that are more likely to find improved employment opportunities when subsidized, such as married women without children, out-of-school young people, and the elderly (Bishop and Haveman, 1978). Conversely, targeting programs toward particular groups of workers, about which employers can have negative preconceptions, may stigmatize the participants and further limit employer interest (Katz, 1998). As noted by Martin (2004), programs that benefit the 'less deserving' might also square less well with the electorate's view of the collective good.

\section{Job eligibility criteria}

Policymakers must also specify criteria for what jobs, with what employers, are eligible for subsidization. These criteria can be made selective to compensate for systematic distortions against, for example, particular firm types, industries, geographical areas, and contract types (or, alternatively, to create new distortions that are deemed socially desirable). Restricting eligibility could be 
motivated on either efficiency or equity grounds, but any gain in these terms must be balanced against increased administrative costs for employers and the state (Bishop and Haveman, 1978).

\section{Data on employment subsidies in the EU LMP database}

A limitation of most comparative studies on ALMP to date is their reliance on the country-level expenditure data published by the OECD (Clasen et al., 2016). These data lack the detailed information on program characteristics required to analyze the dimensions outlined above. In contrast, this article makes use of the program-level data from an ambitious data collection coordinated by the European Commission (henceforth: the EU LMP database), which contains annual observations of expenditures, participants, and program characteristics for approximately 1,000 individual ALMP interventions at the national or regional level in all EU countries plus Norway and reaches back, for some countries, to 1998.

Each intervention in the database is classified into one of six (previously seven) top-level categories: 1. Labor market services, 2. Training, 4. Employment incentives, 5. Sheltered and supported employment and rehabilitation, 6. Direct job creation, and 7. Start-up incentives. Out of those, only categories 4 and 5 contain interventions that satisfy the definition of employment subsidy programs outlined above. Category 4 has three sub-categories, 4.1 Recruitment incentives, 4.2 Employment maintenance incentives, and 4.3 Job-rotation and job-sharing programs, and category 5 has two sub-categories, 5.1 Sheltered and supported employment and 5.2 Rehabilitation. Whereas the latter subcategory can safely be omitted here, none of the others solely contain programs that satisfy the aforementioned definition; hence, more detailed inclusion criteria are needed.

\section{Two datasets and their inclusion criteria}

Because some information relevant to this study can only be extracted manually from open-ended program descriptions, I compose two complementary datasets with slightly different observations and variables. Both are subsets of the EU LMP Program Dataset used by Cronert (forthcoming), which includes all labor market interventions reported to the EU LMP database for the years 1998-2013.

The first, exploratory part of the article uses a smaller dataset with 200 programs observed in 2011, which is the most recent year for which data are reported for all countries. Through manual inspection of the database entries for all approximately 300 programs in categories 4 and 5.1 reported in 2011, I exclude approximately 100 programs that are either 1) supply-side subsidies such as employment bonuses or childcare allowances, 2) subsidies that 
do not cover wage costs but instead provide more limited reimbursements for workplace adjustments made to fit the needs of disadvantaged workers, or 3) subsidies explicitly intended for sheltered employment, meaning employment in enterprises 'established specifically for the employment of people with disabilities or other working limitations' (Eurostat, 2013: 18). Through inspection of the program descriptions, two additional variables on subsidy design can be constructed for a subset of the observations in this dataset.

The second, evaluative part of the study uses a larger dataset with approximately 500 programs observed for one or more years in the period 1998-2013, with two fewer design variables. In this dataset, which is limited from the outset to approximately 4,200 program-year observations reported in categories 4 and 5.1, final inclusion is determined by a semi-automated procedure. First, if neither data on expenditures nor participants are reported for a given program-year observation, the program is considered not in operation and is consequently excluded. ${ }^{3}$ Second, searches are made in program names and descriptions for variations of key terms, such as 'allowance', 'bonus', 'childcare', and 'sheltered'. Inclusion decisions are then made based on inspection of the identified database entries. Lastly, approximately 2 percent of the observations are excluded because they lack necessary data on program duration. After these operations, the sample consists of 3,464 program-year observations, nested in 461 programs.

\section{Operationalization}

Let us turn next to discuss how the variables in these datasets are used to measure the six theoretical design dimensions outlined above.

\section{General form}

The aforementioned program categories can be used to create a dummy variable distinguishing General subsidies from Recruitment subsidies. The latter type is found in sub-category 4.1 Recruitment subsidies, whereas programs with a more general form are found in sub-categories 4.2 Employment maintenance, 4.3 Job rotation and job sharing, and 5.1 supported and sheltered employment. The first two types are, for obvious reasons, not limited to newly hired workers. Programs in the latter category 'typically provide an ongoing support and have no planned duration' (Eurostat, 2013: 18), which implies that in the medium term, all employed workers in the target group are likely to be covered by the subsidy.

\section{Duration}

For almost all employment subsidy programs, the database reports data on the maximum duration and/or typical duration or, alternatively, a note that the 
duration is one-off, variable or unlimited. In cases in which the maximum duration is missing, it is replaced with the typical duration. To construct a categorical variable, I classify one-off programs and programs with a duration of up to 12 months as Short, programs of duration 12 to 24 months as Medium, and those with a duration greater than 24 months as Long. In a fourth category, I categorize programs with Unlimited or variable duration.

\section{Subsidy rate}

For approximately one-half of the manually inspected programs in 2011, the open-ended descriptions contain the data required for constructing variables on Subsidy rate and Subsidy rate form. The rate can be defined either relative to the labor cost (e.g. 50 percent) or in absolute terms (e.g. $€ 4,000$ per year). Accordingly, Subsidy rate divides programs into three groups as follows: Low (less than 50 percent or at most $€$ 4,000 per year), Medium (50-75 percent or at most $€$ 4,000-5,900 per year) or High (more than 75 percent or more than at most $€ 5,900$ per year). Subsidy rate form is coded as either Variable or Fixed. As reported in the Supplementary Materials, the impact of these two variables on the analyses here proves negligible. Hence, I exclude them here to retain the larger sample.

\section{Transfer type}

The database contains a variable that records how resources are transferred to employers and/or workers. I classify Lump-sum payments, Periodic payments and Reimbursements as Direct transfer, whereas Reduced taxes and Reduced social contributions are categorized as Reduced taxes/contributions.

\section{Worker eligibility criteria}

The database distinguishes between two notions of worker target groups. The first one, 'operational target group', is based on the labor market status of the participants. A program may target any combination of the following four groups: (1) 'registered unemployed', (2) 'employed at risk of involuntary job loss', (3) 'other registered jobseekers' - which means 'persons who are unemployed (but do not qualify as registered unemployed), underemployed or inactive' - and (4) 'not registered', which means 'groups who are not in employment or where registration with the PES is not a prerequisite for participation' (Eurostat, 2013: 19). This information is used to create three dummy variables indicating whether a program targets, respectively, the 'Unemployed' (group 1), the 'Employed-at-risk-of-unemployment' (group 2), and the 'Inactive' (groups 3 and/or 4).

Second, the database indicates whether one or more 'detailed target groups' are subject to specific focus in the program. I use these data to create dummy variables for five target groups: 'Long-term unemployed', 'Youth' (aged under 25), 
'Older' (aged over 55), 'Disabled', and 'Other disadvantaged'. The latter collapses 'Immigrants/ethnic minorities', 'Re-entrants/lone parents', and 'Public priorities and other', because these groups are too small to include in the analysis separately. A last dummy, 'All', indicates programs in which no detailed target group is subject to specific focus.

\section{Job eligibility criteria}

Regrettably, the database lacks systematic information on eligibility criteria for jobs and employers. What is possible is to distinguish between programs that, per category definition, require a permanent (open-ended) contract and those that do not. Those that do are in sub-categories 5.1 Sheltered and supported employment or 4.1.1 Permanent recruitment incentives. Accordingly, I create a dummy variable indicating whether a Permanent or a Temporary contract is a requirement for subsidization.

\section{Methodology}

We may now proceed to explore empirically how the major choices in employment subsidy design are combined in programs across Europe. The goal of this exercise is, first, to develop a parsimonious typology of employment subsidy programs by uncovering their underlying dimensionality and, next, to evaluate the plausibility of the proposed typology.

Whereas the selection of the design dimensions above results from deductive reasoning based on existing theory, a more inductive approach is chosen for the remaining part of the typology development process. This choice is motivated by the current state of the research field and the complex nature of employment subsidies. Exploring the multidimensionality of employment subsidy design represents a new endeavor; thus, taking (almost) the full set of observable design choices as a point of departure minimizes the risk of omitting important dimensions. Additionally, given the complexity of subsidy design, developing a typology that explicitly accounts for all choices involved appears an unnecessarily complicated task. A preferable approach at this stage is to first reduce the dimensionality of subsidy design and then develop a more parsimonious typology based on the results of that reduction.

Given the data at hand, MCA appears a particularly suitable tool for this task. Resembling Principal Component Analysis but applied to datasets composed of categorical (rather than continuous) variables, MCA constructs a low-dimensional space that optimally fits the total variation in the data, where the largest part of the variation is accounted for by the first dimension, a smaller part is accounted for by the second dimension, and so on. Pioneered by Bourdieu (1979) to explore the associations between various types of consumption preferences among individuals, MCA has recently been applied within 
policy analysis to develop typologies of national policy regimes, including in the field of diaspora policy, unemployment insurance policy, and family policy (Ragazzi, 2014; Ferragina et al., 2013). To the best of my knowledge, this study is the first to apply MCA to individual policy programs rather than country-level policy regimes.

In the next section, I use MCA to develop a subsidy typology in a three-step procedure. In the first step, the categories of the design variables that are included in the 2011 dataset are plotted in a few principal dimensions that, according to the MCA, jointly account for most of the total variation in the data. Here, '[c]ategories with similar distributions will be represented as points that are close in space, and categories that have very dissimilar distributions will be positioned far apart' (Clausen, 1998: 2). Second, based on the positioning of these categories, I put forward an interpretation of the principal dimensions, which will then form the foundation of the new typology. Third, I produce a plot in which the observed programs are represented as points along these dimensions based on their characteristics. This makes it possible to identify clusters of programs and illuminating cases that are helpful in constructing the typology.

Once having introduced the typology, I provide a first empirical evaluation of its plausibility. If the theoretical propositions that underpin the typology are correct, we would expect to observe that the different types of subsidy programs differ systematically not only in terms of their design but also in terms of their outcomes and starting conditions. Hence, I use the typology to classify a large number of programs and then I statistically test a number of theoretically derived observable implications about differences between the program types.

\section{Results from the MCA \\ Interpretation of the two principal dimensions}

The first part of the analysis is based on the 2011 dataset with 200 programs and 13 variables that together contain 28 categories. An MCA run on this sample, reported in full in the Supplementary Materials, produces five dimensions. Methodological guidelines suggest that we retain the first two, which account for a reasonable 79 percent of the total variation (Le Roux and Rouanet, 2010).

Figure 1 plots the coordinates for each category along the first two dimensions. The next step in the analysis 'amounts to finding out what is similar, on the one hand, between all the elements figuring on the right of the origin and, on the other hand, between all that is written on the left; and expressing with conciseness and precision, the contrast (or opposition) between the two extremes' (Benzécri, 1992: 405). 


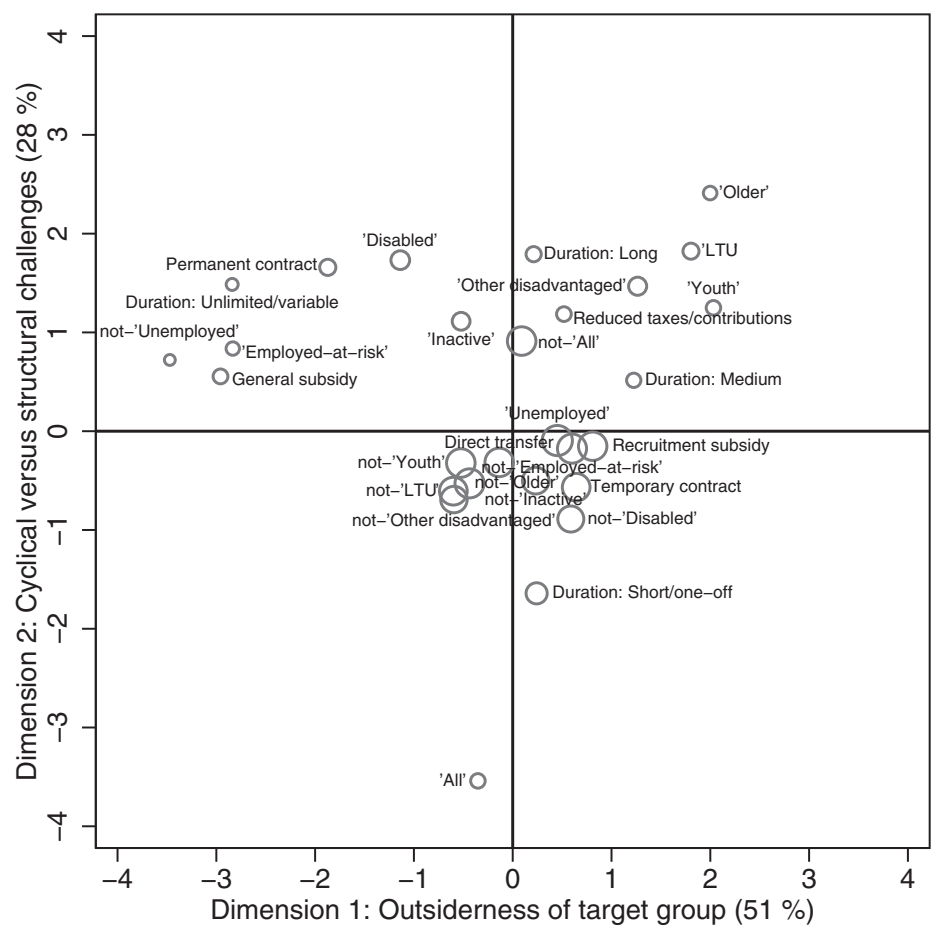

Figure 1 Coordinate plot of the 28 categories in the MCA. The horizontal dimension accounts for 51 percent of the total variation, and the vertical accounts for 28 percent. Each circle's size corresponds to the relative frequency of that category (see Table A1, Supplementary Materials).

A baseline criterion for which categories to consider in the interpretation is those whose contribution to the dimension exceeds or is close to the average contribution (Le Roux and Rouanet, 2010). The first (horizontal) dimension accounts for 51 percent of the variation, and 11 categories make a contribution greater than or close to average. Among these categories, six are located to the left of the origin: not-'Unemployed', General subsidy, 'Employed at risk of unemployment', Duration: Unlimited/variable, Permanent contract, and 'Disabled'. Five are located to the right: 'Youth', 'Older', 'Long-term unemployed', 'Other disadvantaged', and Recruitment subsidy.

This dimension undoubtedly involves program targeting and is probably best understood by reference to the distinction made in the literature on labor market segmentation between 'insiders', who are well-protected incumbent employees, and 'outsiders', who are either unemployed or work through a non-standard employment relationship in the 'secondary labor market' (Emmenegger et al., 2012; Lindbeck and Snower, 2001; Rueda, 2006). The groups to the right of the origin comprise able-bodied but disadvantaged persons who are particularly likely to be in an outsider position for an extended 
period. Recruitment subsidies tend to specifically benefit such outsiders by making it more profitable for firms to recruit from among them, thereby enabling a more equitable distribution of employment (Brown and Koettl, 2015).

To the left of the origin, we find general subsidies intended to maintain rather than initiate employment. Two target groups are associated with these programs. The first group is insiders who, despite having permanent contracts, can at times be at risk of unemployment due to restructuring or other economic difficulties. Although outsiders are often assumed the sole beneficiaries of ALMPs (Rueda, 2006), on such occasions, employment subsidy programs might also be used to compensate employers for not laying off incumbent employees. In effect, programs such as these contribute to insiders' job security and strengthen their position vis-á-vis outsiders (Brown and Koettl, 2015). The second group is workers with disabilities. Although perhaps counter-intuitive, there are two reasons that the disabled cannot be understood as outsiders as commonly conceptualized. ${ }^{4}$

First, according to insider/outsider theory, outsiders may - at least when labor turnover costs and entry-level wages are low - pose a threat to the status of insiders (Lindbeck and Snower, 2001; for a conflicting view see Bonoli, 2013: 52). In contrast, working-age people with disabilities - depending of course on the severity of their impairment - more often face barriers that may prevent them from becoming equally competitive. Although their relative disadvantage crucially depends on the social and institutional context, in all European countries they are still more likely than others to experience unemployment, incomes below the poverty line, and severe material deprivation (Grammenos, 2018). In simplified terms, this suggests that compared to the outsiders, disabled workers in practice more often stand a more limited chance of eventually becoming insiders themselves.

Second, the disabled and the insiders tend to share a politically salient characteristic that distinguishes them from the outsider groups. More often viewed as lacking control over their need of support, they tend to be considered more 'deserving' by the public. The disabled are, almost by definition, understood as incapable of making a living through their own efforts, whereas insiders, when they risk unemployment, are often perceived as victims of forces beyond their control, such as an economic downturn or international competition. For outsiders, particularly the young and the long-term unemployed, there is generally greater doubt among the public concerning whether their neediness is a result of their own actions (van Oorschot, 2000).

The second (vertical) dimension accounts for 28 percent of the variation in the data. Here, 10 categories make an above-average contribution. Above the origin are 'Older', Duration: Long, 'Long-term unemployed', 'Disabled', Permanent contract, 'Other disadvantaged', and not-'All'. Below the origin are 'All', Duration: Short/one-off, and not-'Disabled'. For two reasons, I suggest 
that this dimension is best understood as indicating whether a program is targeted more at counteracting long-term, structural labor market challenges or, alternatively, short-term, cyclical problems caused by economic downturns. ${ }^{5}$

First, Duration: Long, and Permanent contract are located above the origin, whereas Duration: Short/one-off - and Temporary contract, although its contribution is smaller - are found on the opposite side. Programs of the latter type pose less-strict job requirements and are expected to last a shorter time. Thus, they are likely to expand more swiftly once introduced but to induce a more limited and short-lived change to employers' behavior. Hence, they are better-suited to address cyclical demand problems. Second, rather than distinguishing between programs with more or less 'deserving' target groups, this dimension separates programs that initially focus on any particular group from those that do not. This point is evidenced by the location of 'All' and not-'Disabled' below the origin and not-'All' and 'Disabled' above the origin. Although, by definition, all employment subsidy programs are selective to some extent, programs with less-selective eligibility criteria are better suited for operating in economic downturns, when the pool of workers experiencing difficulties includes more persons not belonging to any particular disadvantaged group (Brown and Koettl, 2015).

\section{Illustrative examples from a fourfold typology}

Next step in interpreting an MCA involves inspecting the 'cloud' depicted by the observations when plotted based on their pattern of characteristics. Figure 2 plots the 200 programs along the two aforementioned dimensions and can be used to develop a four-fold program typology.

The upper-right quadrant contains structurally oriented subsidies targeted at able-bodied but unemployed or inactive outsiders - in short, Structuraloutsider programs. These are typically medium- or long-term recruitment subsidies and more often come with temporary contracts than do those specifically targeted at the disabled. A typical case is the Austrian Integration subsidy (Eingliederungsbeihilfen), which is intended to 'encourage employment of certain specific categories of unemployed, especially long-term unemployed and older workers and to increase the employment of women', by means of recruitment subsidies for which both the duration and the rate are variable (up to three years and two-thirds of the labor cost) (European Commission, 2015).

The upper-left quadrant contains long-term or indefinitely renewable subsidies that support the employment of disabled workers. One example is the Belgian Integration premium (La prime d'insertion) established in 1999. This yearlong program, targeted primarily at private employers in Brussels, provides indefinitely renewable subsidies for which the subsidy rate is calculated individually to compensate for the reduced productivity of each employee (up to 65 


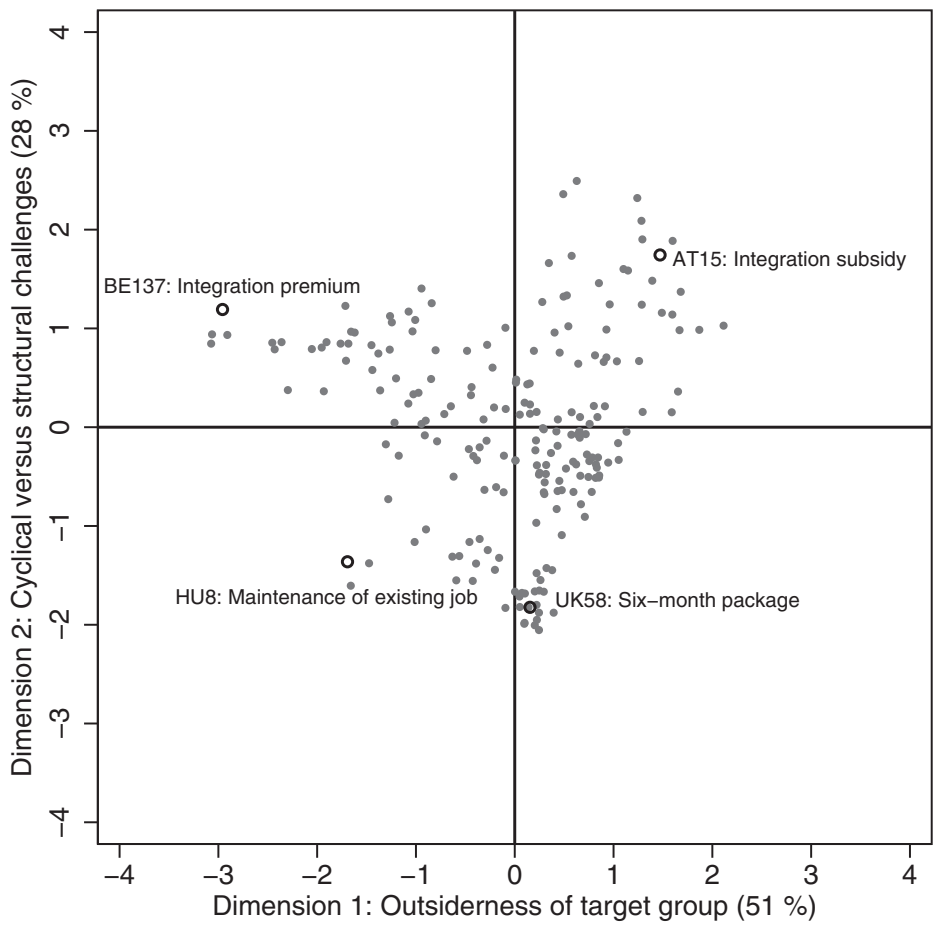

Figure 2 Coordinate plot for the 200 programs observed in 2011. Program names are retrieved from the EU LMP database. A small amount of random noise is dded to all observations to avoid stacking programs with identical scores.

percent) (European Commission, 2015). I label these Structural-disabled programs.

In the lower center-right region are recruitment subsidies that do not restrict eligibility to any particular group, which have short durations and impose few job requirements. A case in point is the Six-month package in operation in the United Kingdom in 2009-2011 as a response to the Great Recession. The program entitled anyone who has been claiming the Jobseeker's Allowance for six months to a voucher to present to prospective employers. If an employer recruits the jobseeker for a position with an expected duration of at least 26 weeks, the voucher entitles the employer to a fixed upfront subsidy of $£_{500}$, which is doubled if the jobseeker does not return to claim the benefit during the 26-week period (European Commission, 2015). I call this type of program Cyclical-general.

A fourth, small cluster of programs, toward the lower-left corner of the plot, is relatively cyclically oriented and scores relatively low on the outsiderness dimension. A useful example is the Hungarian Maintenance of existing job (Munkahelymegoörzés támogatása). Through this 'short-time work' program, employers can receive compensation, for up to 12 months, for between 25 
and 90 percent of the labor costs of incumbent employees where it can be shown that they would otherwise have been made redundant (European Commission, 2015). This program type can be labeled Cyclical-insider.

It is clear from Figure 2 that many programs do not distinctly correspond with any of the four typical cases highlighted above but rather are located in a 'gray zone' in the center of each dimension (Goertz, 2008). Theoretically, this issue is arguably not a cause of concern, as policymakers may certainly prefer a policy design that tries to strike a balance between two opposing alternatives. From an empirical perspective, however, it suggests that whatever operational definition is chosen for classifying programs, the researcher will face some difficult borderline cases.

\section{A first evaluation of the design typology}

This section serves to substantiate the proposed typology by testing a set of observable implications that derive from it and can be observed using the data at hand. To avoid discussing ideal cut-off points, I crudely split the observed programs into four categories corresponding to the four quadrants of Figure 2, based on whether the MCA ascribes to them positive or negative scores on the two dimensions. To increase robustness, I base this analysis on the larger dataset, with 461 programs observed in at least one year between 1998 and 2013. The dimensions generated in the MCA run on this dataset are strikingly similar to those generated in the smaller MCA reported above, suggesting that the two dimensions are robust to sample alterations. ${ }^{6}$ When applicable, the indicators for each program are averaged over the full period of observation. The results are reported in Table 1.

A first observable implication is that the actual duration of participation should be longer for structural programs than for cyclical programs and longer for Structural-disabled programs than for other structural programs. Existing participant data enable estimation of the average duration of participation for approximately 75 percent of the programs. ${ }^{7}$ Table 1 reports the average duration of the median program of each category, which confirms that, first, the duration is longer for structural programs and, second, among them, the duration is particularly long in the case of Structural-disabled programs. Non-parametric equality-of-medians tests confirm that these two differences are statistically significant $(\mathrm{p}<0.000 ; \mathrm{p}=0.039$ ).

Second, in Structural-disabled and Cyclical-insider programs, the prevalence of outsiders among program participants should be lower. An indicator of the share of youth among program participants - the only currently available proxy for outsiderness, reported for two-thirds of the programs - supports this expectation. A t-test confirms that the average rate of youth among participants is lower in these two categories than in the two others $(p<0.000)$. 
TABLE 1. Observable implications of the design-based employment subsidy typology

\begin{tabular}{lccccc}
\hline & $\begin{array}{c}\text { Structural- } \\
\text { outsider }\end{array}$ & $\begin{array}{c}\text { Structural- } \\
\text { disabled }\end{array}$ & $\begin{array}{c}\text { Cyclical- } \\
\text { general }\end{array}$ & $\begin{array}{c}\text { Cyclical- } \\
\text { insider }\end{array}$ & $\begin{array}{c}\text { All } \\
\text { programs }\end{array}$ \\
\hline $\begin{array}{l}\text { Duration of } \\
\text { participation }\end{array}$ & 11.9 & 17.3 & 7.4 & 8.8 & 10.4 \\
$\begin{array}{l}\text { Youth participant } \\
\text { rate }^{\mathrm{b}}\end{array}$ & 23.9 & 15.2 & 35.4 & 19.2 & 25.7 \\
$\begin{array}{l}\text { Cost per participant } \\
\text { c }\end{array}$ & 5,157 & 10,843 & 3,035 & 4,633 & 4,695 \\
$\begin{array}{l}\text { 4-year survival rate } \\
\text { 10-year survival rate }\end{array}$ & 66.7 & 91.5 & 65.9 & 63.9 & 70.5 \\
$\begin{array}{l}\text { Start-year output gap } \\
\text { ( }\end{array}$ & 38.9 & 86.0 & 44.3 & 33.1 & 49.1 \\
\hline
\end{tabular}

For a few programs that shift categories over time, the mode value is used to assign categories. ${ }^{a}$ Months, median program in the category. The average duration for an observed program-year is estimated as the average stock of participants $\times 12$, divided by the total number of entrants. Observations are then averaged for each program. The median is reported to avoid undue influence of outliers generated in instances of very few reported entrants.

${ }^{b}$ Percent of all participants, mean of programs in the category.

${ }^{c} €$, in 2005 prices, median program in the category. An estimate of total participants is given by the average participant stock $\times 12$ divided by the number of entrants.

${ }^{\mathrm{d}}$ Percent. Based on programs started in a year observed in the EU LMP database (6o\% of all programs).

${ }^{e}$ Computed for programs started in a year observed in the EU LMP database, for which output gap data are available ( $51 \%$ of all programs).

Third, public expenditure devoted to each participant should be higher for programs that target relatively more 'deserving' groups, that is, for the Structural-disabled and Cyclical-insider programs. Dividing total expenditure by the estimated total count of participants produces such a measure for approximately 75 percent of all programs, the median of which is reported in Table 1. The expectation is largely borne out in the data; the difference in medians between these two program categories and the other two is substantial and almost statistically significant $(\mathrm{p}=0.086)$.

Fourth, because of the lower perceived 'deservingness' of outsiders, programs targeted at these groups should be comparatively more vulnerable to termination. Similarly, cyclical programs should be more short-lived than structural programs. To test these implications, I estimate Kaplan-Meier survival functions for all programs started in an observed period. Table 1 reports that the survival rate of Structural-disabled programs is considerably higher than that of the other types of programs after both 4 and 10 years, and statistical tests show that these differences are significant. The low survival rate of Structuraloutsider programs deserves a mention. Possibly, these rather narrow, albeit 
structurally oriented, programs tend to have a smaller support coalition than do the broader Cyclical-general programs (cf. Martin, 2004).

Finally, cyclical programs should be more frequently introduced during economic downturns. This expectation is substantiated by an estimate of the average state of the business cycle, measured by the output gap of the economy, in the year the program was started (European Commission, 2017). The average start-year output gap is two to three times higher for the two structural program categories than for the two cyclical categories, and the difference is statistically significant $(\mathrm{p}=0.003)$.

These statistics, albeit merely bivariate, indicate that the four program categories differ in terms of outcomes and starting conditions, in patterns consistent with the proposed interpretation of the two underlying dimensions of employment subsidy design.

\section{Concluding discussion}

This study's key takeaway is that employment subsidies are more versatile than commonly recognized among comparative scholars. Indeed, they might best be conceived of as multi-purpose policy tools of sorts, which policymakers may use as means to rather different distributional ends. These results contradict the notion that 'ALMPs unambiguously benefit outsiders' (Rueda, 2006: 388), which still dominates comparative welfare state research. The results also caution against routinely linking ALMPs to long-term structural transformations of the labor market, demonstrating that employment subsidies are often rather used to counteract short-term cyclical labor-demand slumps.

More specifically, the MCA-generated typology in this article improves upon the typologies of ALMP programs recently applied by Bonoli (2010), Nelson (2013), and Vlandas (2013), in which employment subsidies are assumed a uniform subcategory, yet among which the nature of these assumptions differs. For instance, Nelson (2013) and Vlandas (2013) assume different distributional effects of employment subsidies and arrive at opposite conclusions about which political actors support them more. The analysis reported here would suggest that their respective assumptions hold true for some types of subsidies but not others.

More generally, these results caution against using the administrative program categories in the OECD and EU LMP databases as a basis for the formation and evaluation of theories that involve political actors, corroborating instead Clasen et al.'s (2016) remark that ALMP programs in the same administrative category (not to mention ALMP programs at large) may have very different support coalitions depending on their detailed design. While this is not a case against conducting statistical analyses on disaggregated ALMP 
expenditure data, per se, it highlights the importance of letting theory inform program categorization rather than the other way around.

Lastly, this work may have implications for our understanding of the role of institutional legacies in shaping ALMP portfolios and of the relevance of the post-war welfare regimes in post-industrial labor markets. Unlike the common understanding of ALMPs as conceptually similar and inherently technocratic policies, the versatile understanding of employment subsidies promoted in this article allows for the possibility that the subtleties of programs' design are influenced by the distinct institutional logics that guide policy-making in different countries in ways that matter for their distributional properties. Indeed, case studies by Martin (2004) and, more recently, by Thelen (2014) and Fossati (2018) do raise doubts about the extent to which the advancement of ALMP actually represents a break with existing institutional regimes.

Considering that the European countries differ systematically both in terms of the relative power of insiders and outsiders in the labor market and in terms of policy-makers' inclination towards counter-cyclical management of unemployment, the analytic framework and data presented here may prove useful for a more comprehensive test of the extent to which institutional differences are reflected in the way labor market policy is being designed in different countries. Pending such investigation, a basic implication from this work is that to observe a common trend towards more employment subsidies across Europe is not, per se, sufficient to conclude that there is a substantial convergence in the underlying institutional logics that govern policy-making in different countries.

\section{Supplementary material}

To view supplementary material for this article, please visit https://doi.org/10. $1017 /$ So047279419000126.

\section{Acknowledgements}

I wish to thank participants at the 2017 Midwest Political Science Association conference in Chicago, as well as Linuz Aggeborn, David Autor, Anders Forslund, Daniel Fredriksson, Jonas Larsson Taghizadeh, Karl-Oskar Lindgren, Martin Lundin, Cathie Jo Martin, Moira Nelson, Joakim Palme, Pernilla Tunberger, Kent Weaver, and two anonymous reviewers for constructive comments on earlier versions of this study. Financial support from Uppsala Center for Labor Studies is gratefully acknowledged.

\section{Notes}

1 Italy is omitted in this calculation due to a lack of historic data.

2 Neumark (2013) usefully clarifies the functional differences between demand-side and supply-side subsidies. 
3 This follows Eurostat's (2013:53) definition of when an intervention is in force. Expenditure data are considered 'well completed' (European Commission, 2015); consequently, this operation fully excludes no more than five programs. Re-including them does not affect the MCA performed on this dataset.

4 The insider/outsider literature rarely mentions the disabled. Instead, it mostly focuses on the long-term unemployed, youth, immigrants, and older workers.

5 To some extent, this dimension relates to Van der Aa and Van Berkel's (2014) distinction between demand-led and demand-oriented employment subsidy programs based on how much the program is adapted to existing employer needs.

6 For the 184 observations that are included in both datasets, there is a 0.98 and 0.96 correlation between the coordinates generated for the two dimensions in the small and large MCA, respectively.

7 Because missingness in these data is not randomly distributed, the estimates reported in Table 2 may not generalize to the full sample. Also, the between-group differences in outcomes - which are of primary interest here - may be biased in case missingness is correlated with the outcomes and varies across the compared groups. Reassuringly, for the variables in question, t-tests find no significant difference in missingness between structural and cyclical programs, or between outsider-oriented and non-outsider-oriented programs. Furthermore, restricting the sample to countries with little or no missingness generates results that are broadly consistent with those in Table 2.

\section{References}

Benzécri, J. (1992), Correspondence analysis handbook. New York: Marcel Dekker.

Bishop, J. and Haveman, R. (1978), Targeted employment subsidies: issues of structure and design. Madison: Institute for Research and Poverty, Wisconsin University, Madison.

Bonoli, G. (2010), 'The political economy of active labor-market policy', Politics \& Society, 38 , $4,435-457$.

Bonoli, G. (2013), The origins of active social policy: labour market and childcare policies in a comparative perspective, Oxford: Oxford University Press.

Bourdieu, P. (1979), La Distinction. Critique Sociale du Jugement. Paris: EÉditions de Minuit.

Brown, A.J. and Koettl, J. (2015), 'Active labor market programs- employment gain or fiscal drain?', IZA Journal of Labor Economics, 4, 12, 1-36.

Card, D., Kluve, J. and Weber, A. (2015), What works? A meta analysis of recent active labor market program evaluations. Cambridge: National Bureau of Economic Research.

Clasen, J., Clegg, D. and Goerne, A. (2016), 'Comparative social policy analysis and active labour market policy: Putting quality before quantity', Journal of Social Policy, 45, 1, 21-38.

Clausen, S.-E. (1998), Applied correspondence analysis: an introduction. Thousand Oaks: SAGE Publications.

Cronert, A. (forthcoming), 'Unemployment reduction or labor force expansion? How partisanship matters for the design of active labor market policy in Europe', Socio-Economic Review, doi: 10.1093/ser/mwxo14.

Cronert, A. (2018), 'Accommodation or extraction? Employers, the state, and the joint production of active labor market policy', Politics \& Society, 46, 4, 539-569.

Eichhorst, W., Kaufmann, O., Konle-Seidl, R. and Reinhard, H.-J. (2008), 'Bringing the jobless into work? An introduction to activation policies', In: W. Eichhorst, O. Kaufmann, and R. Konle-Seidl (Eds.), Bringing the jobless into work? (pp. 1-16), Berlin and Heidelberg: Springer.

Emmenegger, P., Häusermann, S., Palier, B. and Seeleib-Kaiser, M. (2012), The age of dualization: the changing face of inequality in deindustrializing societies, Oxford: Oxford University Press. 
European Commission (2014), Stimulating job demand: the design of effective hiring subsidies in Europe, Luxembourg: Publications Office of the European Union.

European Commission (2015), Labour market policy (source: DG EMPL), http://ec.europa.eu/ eurostat/cache/metadata/en/lmp_esms.htm [accessed 16.10.2017].

European Commission (2017), The AMECO database. European Commission: DG ECFIN, http://ec.europa.eu/economy_finance/ameco [accessed 16.10.2017].

Eurostat (2013), Labour Market Policy Statistics. Methodology 2013. Luxembourg: Publications Office of the European Union.

Ferragina, E., Seeleib-Kaiser, M. and Tomlinson, M. (2013), 'Unemployment protection and family policy at the turn of the 21st century: a dynamic approach to welfare regime theory', Social Policy \& Administration, 47, 7, 783-805.

Fossati, F. (2018), 'How regimes shape preferences. A study of political actors' labour market policy preferences in flexicurity and dualizing countries', Socio-Economic Review, 16, 3, 523-544.

Goertz, G. (2008), Concepts, theories, and numbers: a checklist for constructing, evaluating, and using concepts or quantitative measures. In: J.M. Box-Steffensmeier, H.E. Brady, and D. Collier (Eds.), The Oxford handbook of political methodology (pp. 97-118), Oxford: Oxford University Press.

Gore, T. (2005), 'Extending employability or solving employers' recruitment problems? demand-led approaches as an instrument of labour market policy', Urban Studies, 42, 2, 341-353.

Grammenos, S. (2018), European comparative data on Europe 2020 \& people with disabilities, Brussels: Academic Network of European Disability Experts (ANED).

Graziano, P.R. (2012), 'Converging worlds of activation? Activation policies and governance in Europe and the role of the EU', International Journal of Sociology and Social Policy, 32, $5 / 6,312-326$.

Ingold, J. and Stuart, M. (2015), 'The demand-side of active labour market policies: a regional study of employer engagement in the work programme', Journal of Social Policy, 44, 3, 443-462.

Jessop, B. (1993), 'Towards a Schumpeterian workfare state? Preliminary remarks on post-fordist political economy', Studies in Political Economy, 40, 7-40.

Jessop, B. (1999), 'The changing governance of welfare: recent trends in its primary functions, scale, and modes of coordination', Social Policy \& Administration, 33, 4, 348-359.

Katz, L.F. (1998), Wage subsidies for the disadvantaged. In: R.B. Freeman and P. Gottschalk (Eds.), Generating jobs: how to increase demand for less-skilled workers (pp. 21-53), New York: Russell Sage Foundation.

Le Roux, B. and Rouanet, H. (2010), Multiple correspondence analysis. Thousand Oaks, CA: Sage.

Lindbeck, A. and Snower, D.J. (2001), 'Insiders versus outsiders', Journal of Economic Perspectives, 15, 1, 165-188.

Martin, C.J. (2004), 'Reinventing welfare regimes employers and the implementation of active social policy', World Politics, 57, 1, 39-69.

Nelson, M. (2013), 'Making markets with active labor market policies: the influence of political parties, welfare state regimes, and economic change on spending on different types of policies', European Political Science Review, 5, 2, 255-277.

Neumark, D. (2013), 'Reconsidering hiring credits', Journal of Policy Analysis and Management, 32, 1, 142-171.

OECD. (2017), Dataset: public expenditure and participant stocks on LMP. Paris: OECD. http://stats.oecd.org/ [accessed 28.01.2017].

Ragazzi, F. (2014), 'A comparative analysis of diaspora policies', Political Geography, 41, 74-89. Rueda, D. (2006), 'Social democracy and active labour-market policies: insiders, outsiders and the politics of employment promotion', British Journal of Political Science, 36, 3, 385-406.

van Oorschot, W. (2000), 'Who should get what, and why? On deservingness criteria and the conditionality of solidarity among the public', Policy \& Politics, 28, 1, 33-48. 
Thelen, K. (2014), Varieties of liberalization and the new politics of social solidarity, New York: Cambridge University Press.

Van der Aa, P. and Van Berkel, R. (2014), 'Innovating job activation by involving employers', International Social Security Review, 67, 2, 11-27.

Vlandas, T. (2013), 'Mixing apples with oranges? Partisanship and active labour market policies in Europe', Journal of European Social Policy, 23, 1, 3-20.

Weishaupt, T.J. (2011), From the manpower revolution to the activation paradigm: explaining institutional continuity and change in an integrating Europe, Amsterdam: Amsterdam University Press. 